\title{
The Future of Combating Climate Change: How to Share the Burden Among Countries?
}
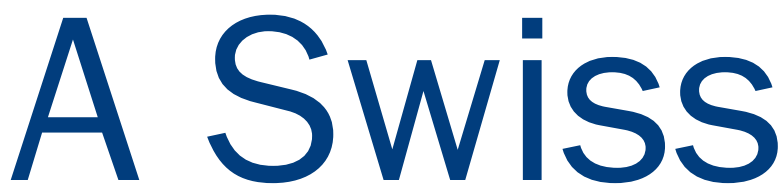

\section{Perspective}

I would like to contribute to the ongoing discussion on this topic by adding two elements. ${ }^{1}$ Firstly, it might be interesting to shed some light on how another small country - Switzerland - tackles the issue of climate change. Secondly, it is useful to remember at all times that it is in the negotiation room itself, where- regardless of all the statements by governments or by scientists outside of that room - the decisions

His Excellency Dr Beat Nobs has been the Ambassador of Switzerland to New Zealand since 2005. From 1993 to 1997 he was Deputy Permanent Representative of Switzerland to the United Nations Environment

Programme (UNEP), and from 1997 to 2005 he was the first Ambassador of Switzerland for the Environment and chief negotiator for Switzerland in the field of environmental diplomacy, where he negotiated the Kyoto Protocol for Switzerland. He is a former vice-president of the UNFCCC and the UNEP, and founder of the Environmental Integrity Group, one of the negotiating groups in climate change diplomacy, encompassing Switzerland, Mexico and South Korea.

1 This article is written in my personal capacity and may not necessarily correspond to the official position of the Swiss government. It is based my remarks at the Post-2012 Burden Sharing symposium, 29 July 2008, Wellington, jointly hosted by the European Union Centres Network and the Institute of Policy Studies. on a future climate regime will finally be taken. What are the conditions to be met for a breakthrough at the Copenhagen conference to be held in December 2009 under the United Nations Framework Convention on Climate Change (UNFCGC)?

\section{Switzerland and climate change}

Switzerland has a population of 7.6 million, per capita $\mathrm{CO}_{2}$ emissions of about 7 tonnes and has already experienced a temperature increase of approximately $1.5^{\circ} \mathrm{C}$ since the early 20th century (i.e. much more than the global average temperature increase of $0.8^{\circ} \mathrm{G}$ ). As an alpine country, Switzerland is particularly vulnerable to climate change and knows it. A series of extreme weather events, such as storms, heat waves and torrential rains, have caused great damage and great cost for many towns and villages in the country. Worse is to be expected. Increased precipitation or the thawing of the permafrost soils in the Alps, for example, poses increasing risks for an increase of devastating avalanches, floods or mud slides that cause not only damage to the lives and livelihoods of people but bring about structural damage to transport and communication infrastructure, buildings and winter sports installations such as cable cars and ski lifts.

A policy that in a very tangible and concrete way addresses the adverse effects of climate change both at the national and international levels has therefore been widely accepted in Switzerland.

Climate policy in Switzerland is incorporated into a number of sectoral policies, such as energy, transport and agriculture policies. The most important ones are the National Energy Act (in force since 1998) and the $\mathrm{CO}_{2}$ Act of 2000. The Kyoto Protocol was ratified in 2003. Under the Kyoto Protocol, Switzerland is to reduce its greenhouse gas (GHG) emissions by $8 \%$ by the end of 2012 compared to 1990 emission levels. 
To limit the use of fossil fuels - which account for about $75 \%$ of Switzerland's GHG emissions - the $\mathrm{CO}_{2}$ Act stipulates $\mathrm{CO}_{2}$ emission reduction targets for 2010 compared to 1990 levels. Apart from an overall reduction target of $10 \%$, emissions from heating/process fuels are to be lowered by $15 \%$ and emissions from transport by $8 \%$. In order to achieve its targets, a carrot and stick approach is applied. Private companies negotiate voluntary but concrete reduction agreements with the government (i.e. the Federal Office of Energy) individually or via the newly established Energy Agency for the Economy.

As any sound emission-reduction policy will not kick in the first day the measures enter into force, Switzerland set a number of benchmarks both in quantity and time for its emission reductions. One such was the target of a reduction by $6 \%$ for heating/process fuel by 2007. As this benchmark was unfortunately not achieved as set out in the $\mathrm{CO}_{2}$ Act, a $\mathrm{CO}_{2}$ levy of CHF 12.-/tonne $\mathrm{CO}_{2}$ emissions (= 3 cents per litre) was imposed as of 1 January 2008. Due to this measure, but certainly due also to the price hike for oil on the international spot markets, 2007 proved to be more successful and $\mathrm{CO}_{2}$ emissions were reduced by another $7 \%$, down to $88.8 \%$ of 1990 levels.

The situation will be continuously monitored in order to determine whether the levy needs to be increased in 2009 . Since the levy is not a tax, its proceeds will be distributed back to the population by way of a health insurance refund and to companies by way of a refund on social security premiums which are collected on wages.

As far as transport fuel is concerned, a different approach has been used thus far. On the initiative of oil and car importers, the Swiss Climate Cent Foundation was established. They were given the right to add a special surcharge ('climate cent') of currently 1.5 cents per litre at the pump: the proceeds are to be used for climate projects in Switzerland, but also to acquire Emission Reduction Units (ERUs) through international projects under the Kyoto flexible mechanisms (i.e. Joint Implementation and the Clean Development Mechanism).

The above-mentioned policy measures must suffice for Switzerland to be in compliance as to its commitments under the Kyoto Protocol. There is no a legal provision to use tax funds to buy ERUs in order to meet our international commitments; nor do we think such an approach to be future oriented, as it would not increase the worldwide competitiveness of Swiss businesses in the promising energy efficiency market and other sectors, where cost-saving gains can be made. Climate change undoubtedly poses problems for certain industries, like cement, but its cost induced technology drive presents a huge field of opportunity for a country like ours, where the economy is largely knowledgebased, with companies constantly trying to compete at a global level.
Of course, given the fact that the end of the first commitment period under Kyoto (on 31 December 2012) is approaching very fast, Switzerland, like every other country, is both at the national and international level in the process of defining its next steps. One might advocate, that being small with low overall emissions we should be offered a free ride or less stringent conditions than larger emitters. We don't share this view. As an Annex I country under the Kyoto Protocol, you are only taken seriously as an active participant in the negotiations if you meet your Kyoto commitments to the letter and are willing to do your bit.

As far as the national arena is concerned, Switzerland has embarked on a consultation process on how best to amend the national $\mathrm{CO}_{2}$ law. Internationally, we think that the offer of the European Union to reduce $\mathrm{CO}_{2}$ equivalent emissions by $20 \%$ by 2020 compared to 1990 levels is a sound starting point from which to enter into negotiations. However, as mitigation efforts will only kick in at a very late stage, adaptation to climate change is crucial. This is why we have proposed a new international adaptation scheme, funded via a $\mathrm{CO}_{2}$ levy on emissions. This Swiss proposal, based on the principle of 'common but differentiated responsibilities' and the polluter-pays principle, will be presented in detail at one of the next meetings of the UNFCCG.

Switzerland has not yet, however, officially presented its position on how - on a global scale - the mitigation challenge should be tackled by the international community post 2012.

\section{A personal view on the mitigation challenge}

Let me share some thoughts on this matter in a purely personal capacity and not as the Ambassador of Switzerland to New Zealand.

As mentioned above, the final result which hopefully will be achieved by the negotiators at the 15 th conference of the parties to the UNFGCG in Copenhagen at the end of 2009 (COP 15) will depend much on the dynamics as they will be playing out in the negotiation rooms themselves. This will not be the first time. It is important to remember that all major breakthroughs in climate change negotiations in the past came about in that fashion. I refer to COP 3 in Kyoto in December 1997, COP 6 in Bonn in July 2001, and COP 7 in Marrakech in December 2001 where the Marrakech Accords were agreed upon. 
Governments therefore will have to prepare accordingly. The issue of climate change merits the highest attention by governments around the world. Due to its potentially dire consequences across a wide array of other areas, such as agriculture, security, migration and so forth, the issue of climate change is increasingly taking centre stage in the international political arena and it is recognised by many as one of the, if not the, major foreign policy challenges of the 21 st century. Political coherence within government policies and consequently between government departments is therefore as important as coherence between political statements made to the national and international public on the one hand and the unified instructions given to the delegations on the other hand.

It goes without saying that governments never put all their cards on the table in the initial phases of the negotiations. However, governments are well advised to define a bottom line. It is unfortunately not unusual to see official delegations in disarray during negotiations, when rifts within the delegation become obvious or when delegations are unprepared for the twists and turns of events. Since decisions are taken by consensus, pressure usually increases on a country that finds itself in the usually uncomfortable situation to hold out all alone for reasons of national 'special circumstances'. Especially smaller countries are well advised to plan for the unforeseen and, unfortunately, also for the unwelcome.

The media and the public of a country have to play a role, too: the media in taking a very close interest in what is happening during the negotiations and by reporting in great detail to the public not only their own national positions, but the actual state of play. This helps governments to make their audience understand that international negotiations are a give-and-take for everyone, and that a compromise - as painful as it might seem at the time - might be inevitable given the dynamics and is in the long run in the interest of the country.

But what is the interest of a country? In international negotiations, it is a matter of course, that a country pursues its clearly defined national interests. In an increasingly globalized world, where problems and solutions alike are globalized, the sheer concept of 'national interest' might need to be broadened. A new concept of 'global domestic policy' might need to be put forward. This means that governments increasingly realise that an internationally achieved sustainable solution to a global issue - such as climate change - over the longer term becomes as important as, or even more so, to a country's well-being and future than short- to mid-term national interests usually pursued in international negotiations. To apply this to climate change: it is in the interest of a small country to accept a solution in the end, if the solution contributes substantially to the reduction of emissions among large-scale emitters, even if in the process a particular objective of that small country cannot be realized and therefore the result of the negotiations, at first glance at least, might be rather painful from a purely traditional viewpoint of the definition of national interest.

In the lead up to important conferences, it is crucial that governments communicate possible outcomes to the public in order to create the necessary acceptance. At the World Trade Organisation Doha Round negotiations in Geneva in mid-2008, the possibly costly impact of the negotiating packet on Switzerland's agricultural sector was widely discussed in the Swiss media, while it was pointed out at the same time that the overall gains for the Swiss economy at large would outweigh losses incurred by the agricultural sector alone.

However, while small countries might, in the best of cases, play a creative and constructive role - as Switzerland was able to do in its role as chair of the negotiations leading up to the Marrakech Accords - given the size of emissions it is obvious that the large emitters must take the lead and must substantially contribute to mitigation efforts under the post-2012 climate change regime. This, of course, includes the United States, but increasingly also the large developing countries, such as China, India and Brazil, as their emissions, both in total and per capita, are growing. By 2015 half of the emissions will originate from the large emerging economies of the developing world. They must, according to their emissions profile, actively participate not only in the problem but also in the solution. This is in their best interest, given the fact that the brunt of the cost of the damage caused by climate change will have to be born by developing countries. To remain in a state of denial will make matters worse over time.

Unfortunately, the current state of affairs indicates a rocky path ahead. A close look at the declaration adopted in Bali at COP 13 in December 2007 - which in its general approach is very promising - reveals little substance and progress beyond well crafted words.

If we want to achieve an outcome in Copenhagen that seriously contributes to an overall emission reduction at the global level in the next decade, the way forward, seems to be clear:

One major step must be to revise the current split of membership under the UNFGCG between Annex I and non-Annex I countries, and - following a proposal made by Japan at the recent climate talks in Bangkok - it should be replaced by a system whereby the actual emission profile of a country is taken into account. A new set of groups could then be established, with large emitters, medium-size emitters and small emitters given various and differentiated responsibilities according to the principle of 'common but differentiated responsibilities':

It is clear that the current Annex I countries, given their commitments under the Kyoto Protocol, would remain in the group of countries with the most stringent reduction targets to be negotiated under the new regime.

They would, however, be joined by countries with high per capita emissions that have not had mitigation commitments under the Kyoto Protocol. In order to make this more acceptable - a tall order anyway - no-regret targets and individual solutions according to the national 
emission profiles would have to be negotiated, supported by a compliance regime, which might be less punitive in the case of non compliance than the current one under the Kyoto Protocol is. Also, additional financial means and a practical solution to promote the transfer of state-of-the-art technology are necessary.

A second tier of newly developed countries would - in a first phase - be included in this global mitigation regime on a voluntary basis, with the provision to integrate them fully at a later stage if their emissions keep growing.

The third group would consist of countries, such as small island developing states or least developed African countries, with a very low per capita emissions profile and a very low GDP. No emission-reduction commitments on their part would be envisaged under the regime.

Of course, the broadly successful Kyoto mechanisms, which allow for joint action across borders and have given a price to $\mathrm{CO}_{2}$ equivalent, need to be preserved under all circumstances.

The second step that then needs to be taken is the determination of the individual national emission reductions. Rather than just cutting emissions along the lines of the
Kyoto Protocol as we know it, a logical - albeit politically very difficult - approach seems to be a budget approach. If there is a need to reduce global emissions by $50 \%$ by $2050-$ as is very conservatively indicated by the Intergovernmental Panel on Climate Change - in order to achieve certain climate stabilisation objectives, then an emissions-budget can be calculated for every country, based, for practical purposes, on a mix of factors. This would then allow national emission reduction targets to be calculated - or indeed in the cases of countries with low per capita emissions, such as India, even emission growth targets.

This method seems to be - from a purely physical point of view - a practical one if we are serious in trying to implement the overall objective of UNFCGG, namely 'to stabilize greenhouse gas concentrations in the atmosphere at a level that would prevent dangerous anthropogenic interference with the climate system' (Article 2, UNFCCG).

Whether physical logic can be successfully transferred into political logic remains to be seen. All we can do is to try. We have no time to lose.

\section{Towards A New Global Climate Treaty Looking Beyond 2012

$$
\text { Edited by Jonathan Boston }
$$

Climate change poses huge ethical, political, economic and technical challenges. The global community had taken initial steps to address these challenges, but this falls far short of what will be needed in the years ahead. The Kyoto Protocol, negotiated in 1997 under the United Nations Framework Convention on Climate Change, requires industrialised countries to reduce their emissions by an average of $5 \%$ below 1990 levels during the first commitment period (2008-12).

With the first commitment period ending in barely four years, the international community must now decide what is the right mix of policies and commitments needed to build the momentum required to reverse the growth of greenhouse gas emissions and help nations adapt to the unavoidable impact of climate change. Much is at stake not least the well-being of many future generations of humanity.

This book explores the critical policy issues that will need to be addressed during the forthcoming negotiations for a post-2012 climate treaty. Particular attention is given to the implications of such a treaty for New Zealand including the issues affecting the energy, agricultural and forestry sectors.



An Institute of Policy Studies publication edited by Jonathan Boston

Published - November 2007

Format - B5 Paperback, pp 258

ISBN 1-877347-22-1 Price - \$30.00 (including P\&P within New Zealand)

Place your order by email, phone, fax or mail to:

Institute of Policy Studies, Victoria University of Wellington

Email ips@vuw.ac.nz Telephone +64 44635307 Fax +64 44637413

PO Box 600, Wellington, New Zealand

An invoice will be issued with your order

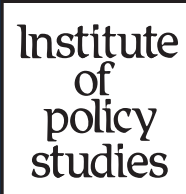

